\title{
PELATIHAN PENYUSUNAN LAPORAN KEUANGAN UNTUK KOPERASI SANG BUMI RUWA JURAI
}

\author{
Ani Pujiati*1, Ahiruddin ${ }^{2}$, Ade Sandra Dewi ${ }^{3}$, Lidia Anggraini ${ }^{4}$ \\ ${ }^{1}$ Universitas Sang Bumi Ruwa Jurai \\ e-mail: "1anipujiati@gmail.com, \\ 2ahiruddin480@gmail.com, ${ }^{3}$ 142.adedewi@gmail.com, ${ }^{4}$ lidiaanggraini0014@gmail.com
}

\begin{abstract}
Abstrak
Laporan keuangan berfungsi sebagai alat untuk meganalisis kinerja keuangan yang dapat memberikan informasi tentang posisi keuangan, kinerja dan arus kas, sehingga dapat dijadikan sebagai dasar dalam membuat keputusan ekonomi. Tujuan dari pengabdian ini adalah untuk memberikan pelatihan penyusunan laporan keuangan dan perancangan laporan keuangan secara sederhana pada Koperasi Sang Bumi Ruwa Jurai Kelurahan Jagabaya 2, Wayhalim, Bandar Lampung. Metode yang digunakan dalam penyuluhan ini adalah ceramah, diskusi interaktif, demonstrasi dan latihan pembuatan prosedur keuangan. Peserta penyuluhan ini yakni pembina koperasi, ketua koperasi, sekretaris koperasi, bendahara koperasi, anggota koperasi, dan mahasiswa. Hasil yang dicapai setelah mengikuti penyuluhan prosedur laporan keuangan, yaitu peserta mampu membuat laporan keuangan koperasi sesuai standar akuntansi sehingga dapat dipertanggungjawabkan.
\end{abstract}

Kata kunci: Pelatihan, Laporan Keuangan, Koperasi, Sang Bumi Ruwa Jurai

\begin{abstract}
Financial statements function as a tool to analyze financial performance that can provide information about financial position, performance and cash flows, so that they can be used as a basis for making economic decisions. The purpose of this service is to provide training in the preparation of financial reports and the design of simple financial statements at the Sang Bumi Ruwa Jurai Cooperative, Jagabaya 2 Village, Wayhalim, Bandar Lampung. The methods used in this counseling are lectures, interactive discussions, demonstrations and exercises for making financial procedures. The participants of this counseling are cooperative builder, cooperative chairman, cooperative secretary, cooperative treasurer, cooperative members, and students. The results achieved after following the counseling on financial reporting procedures, namely participants were able to make cooperative financial reports according to accounting standards so that they could be accounted for.
\end{abstract}

Keywords: Training, Financial Reports, Cooperatives, Sang Bumi Ruwa Jurai

\section{PENDAHULUAN}

Peran perempuan sebagai penggerak [1] pemberdayaan masyarakat desa saat ini telah banyak dilakukan seiring dengan semakin menguatnya partisipasi mereka dalam berbagai bidang kehidupan [2]. Perempuan dapat menjadi motor penggerak sistem sosial, pendidikan, ekonomi dan juga budaya [3] yang kuat jika diberikan peran untuk mengambil bagian dalam proses pembangunan masyarakat. Hal inilah yang ditunjukkan oleh pengrajin perempuan Koperasi Sang Bumi Ruwa Jurai di Kelurahan Jagabaya II, Kecamatan Way Halim, Kota Bandar Lampung, Lampung.

Kelompok ini berdiri sejak 18 Maret 2021 dengan jumlah anggota sebanyak 10 orang. Saat ini Koperasi Sang Bumi Ruwa jurai memiliki visi untuk mewujudkan lembaga sosial ekonomi yang mandiri dan berdaya saing sebagai penggerak ekonomi yang berwawasan lingkungan dan berkelanjutan. Berwawasan 
lingkungan merupakan wawasan yang tidak mengabaikan kelestarian lingkungan, menjaga keharmonisan lingkungan dan sumber daya [4]. Disebut berwawasan lingkungan karena memaksimalkan nilai guna dari limbah tali kelam yang diperoleh dari perusahaan.

Kelompok ini bergerak di bidang usaha simpan pinjam. Selain itu, kelompok ini memiliki unit usaha tas sangke yang telah mampu memproduksi 6.000 buah tas sangke perbulan yang diharapkan produksinya bisa meningkat menjadi 7.200 buah. Usaha kelompok perempuan ini bukan berarti berjalan tanpa masalah. Mereka masih menghadapi beberapa kendala seperti kurangnya modal kerja untuk menunjang aktivitas volume produksi dan biaya pemasaran [5], kesulitan dalam mencari bahan baku yang akan diproses [6], tenaga kerja kurang profesional karena keahlian yang dimiliki hanya berdasar pengalaman [7], produk yang dihasilkan tidak mempunyai variasi dan cendrung monoton [8], belum melakukan pembukuan yang tertata dengan baik sehingga sulit untuk menentukan perolehan hasil usahanya [9], serta kelembagaan belum disusun dengan baik [10]. Namun mereka merasa punya peluang yang besar dalam pengembangan usaha ke depan karena ketersediaan bahan baku yang dapat dicari bersama melalui kerjasama ke perusahaanperusahaan. Peluang yang lain adalah masih sedikitnya pengrajin yang mampu membuat tas sangke sehingga berapapun hasil produksi dari pengrajin selalu terjual. Selain itu, mereka juga mengakui bahwa tas sangke ini melestarikan alam yang dapat mengurngi limbah tali dari perusahaan.

Koperasi ini berharap menjadi pemersatu masyarakat Kelurahan Jagabaya II sehingga bisa menjadi bukti bahwa modal sosial terjaga dan terpelihara [11] di desa ini. Kelompok usaha ini berupaya untuk meningkatkan nilai-nilai kearifan lokal dan mampu mengelola limbah tali kelam menjadi tas sangke. Pemanfaatkan limbah tali kelam yang mempunyai nilai ekonomi yang berkelanjutan.

Dari beberapa kendala yang sudah disebutkan di atas, kendala utama yang dialami oleh koperasi ini adalah pada penyusunan laporan keuangan, dikarenakan kurangnya SDM yang memiliki kemampuan dalam bidang akuntansi dan kurangnya alokasi waktu dalam menyusun laporan keuangan. Menghadapi kendala tersebut Fakultas Ekonomi Universitas Sang Bumi Ruwa Jurai berupaya melakukan kegiatan pengabdian masyarakat dalam bentuk workshop pelatihan membuat laporan keuangan secara sederhana kepada pemilik koperasi tersebut.

Serangkaian pelatihan dan pendampingan yang diadakan oleh Universitas Sang Bumi Ruwa Jurai dan mitra diharapkan bisa semakin menguatkan hal-hal untuk upaya nyata untuk menjaga kelestarian lingkungan hidup [12] dan mewujudkan prinsip pembangunan berkelanjutan [13]. Hal ini sejalan dengan upaya Universitas Sang Bumi Ruwa Juraidalam mendukung upaya 
pembangunan berkelanjutan masyarakat. Oleh karena itu, tujuan pengabdian ini adalah untuk memberikan pelatihan penyusunan laporan keuangan dan perancangan laporan keuangan secara sederhana pada Koperasi Sang Bumi Ruwa Jurai.

\section{METODE}

Metode yang digunakan dalam kegiatan pelatihan ini adalah metode ceramah dan diskusi. Metode ceramah digunakan oleh pemateri unuk menjelaskan materi yang berkaitan dengan materi pengelolaan keuangan koperasi. Selanjutkan dilakukan diskusi untuk memperdalam materi bahasan baik bentuk tanya jawab secara perorangan maupun perwakilan peserta.

Pelaksanaan pelatihan ini selama dua hari pada tanggal 14 dan 18 Maret 2021 di Sekretariat Koperasi Sang Bumi Ruwa Jurai. Kelurahan Jagabaya II, Kecamatan Way Halim, Kota Bandar Lampung, Lampung, pukul 08.0012.00 WIB.Pelatihan ini diikuti oleh 30 peserta dari Koperasi Sang Bumi Ruwa Jurai, Kelurahan Jagabaya II, Kecamatan Way Halim, Kota Bandar Lampung, Lampung. Peserta pelatihan terdiri dari Pembina Koperasi, Ketua Koperasi, Sekretaris Koperasi, Bendahara Koperasi, anggota koperasi, dan mahasiswa.

\section{HASIL DAN PEMBAHASAN}

Berdasarkan hasil survey dan konsultasi dengan ketua koperasi maka pada tanggal 14 dan 18 Maret 2021 telah dilaksanakan kegiatan sosialisasi dan pelatihan laporan keuangan koperasi, dalam meningkatkan pemahaman para pengelola koperasi dalam membuat laporan keuangan Koperasi Sang Bumi Ruwa Jurai.

Kegiatan penyuluhan Penyusunan Laporan Keuangan Koperasi Sang Bumi Ruwa Jurai dilaksanakan di sekretariat Koperasi di Kelurahan Jagabaya II. Peserta pelatihan terdiri dari Pembina Koperasi, Ketua Koperasi, Sekretaris Koperasi, Bendahara Koperasi, anggota koperasi, dan mahasiswa. Pelatihan pada hari pertama tanggal 14 Maret 2021 diawali dengan pemateri Dr. Ahiruddin, S.E.,M.M. yang juga merupakan Dekan Fakultas Ekonomi Universitas Sang Bumi Ruwa Jurai. Beliau memberikan materi tentang manfaatnya laporan keuangan bagi koperasi terkait dengan transparansi dan pertanggungjawaban. Pemateri selanjutnya adalah Ani Pujiati, S.E., M.E.Sy. membahas materi yang berkaitan dengan laporan keuangan koperasi, antara lain berupa Angsuran Pinjaman, Tabungan Wajib Anggota, Tabungan Pokok Anggota, dan Pinjaman Pembelian Barang. Peserta diajak berdiskusi dan demonstrasi terkait materi tersebut.

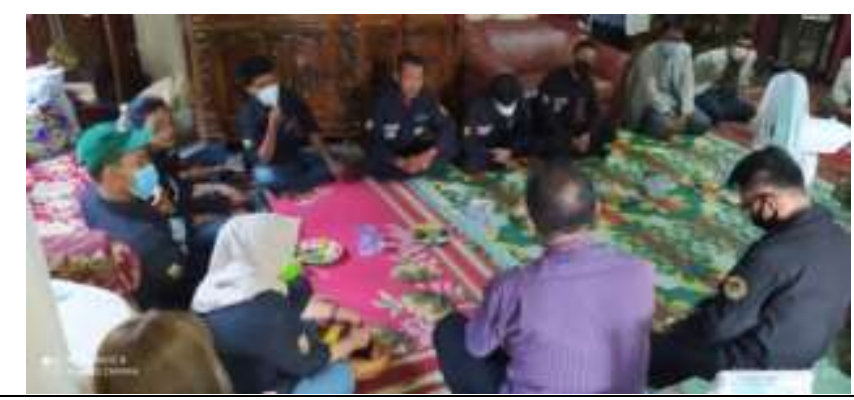


Gambar 1. Pemaparan Materi pada hari pertama

Pada hari kedua sebelum pelatihan, dibuka oleh sambutan dari Anggota DPRD Provinsi Lampung H. Ade Utami Ibnu, S.E. membahas tentang manfaat koperasi bagi peningkatan pendapatan dan perekonomian masyarakat, khususnya di Kelurahan Jagabaya II. Acara berikutnya adalah pemberian materi pelatihan penyusunan laporan keuangan, yaitu Laporan Keuangan Bulanan, Buku Besar, Buku Kas Kecil (jika ada), dan Rekonsiliasi Bank. Setelah itu para peserta diajak berdialog dengan tanya jawab menyangkut materi yang telah disampaikan. Peserta juga diajak untuk mencoba membuat laporan keuangan sehingga bisa mengaplikasikan laporan keuangan secara langsung.

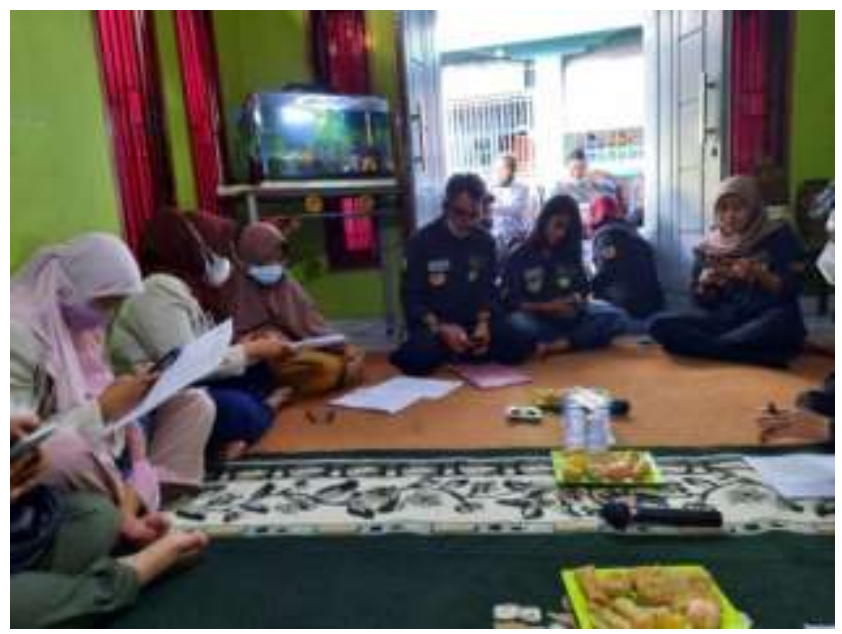

Gambar 2. Pemaparan Materi pada hari kedua

Berdasarkan kegiatan di lapangan, Pengetahuan serta serta minat dari para pengelola usaha Koperasi Sang Bumi Ruwa Jurai sangatlah tinggi, terlihat dari antusias para peserta yang aktif dalam kegiatan. Selain itu, nampak bahwa para peserta kegiatan pelatihan sangat memahami penjelasan materi yang disampaikan. Hal ini dibuktikan dengan berbagai macam pertanyaan yang diajukan serta diskusi.

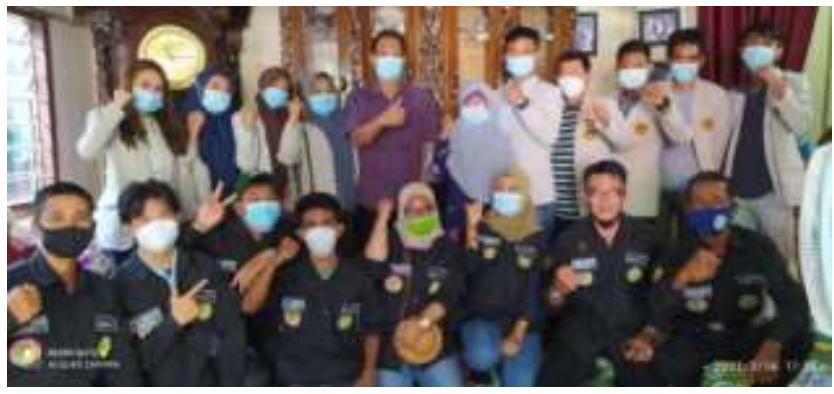

Gambar 3. Foto Bersama dengan Peserta di akhir kegiatan

\section{SIMPULAN}

Pelatihan Penyusunan Laporan Keuangan berjalan sangat aktif dan komunikatif. Awal pelatihan diberikan permainan untuk meningkatkan motivasi terhadap peserta yang merupakan pengurus yang terkait dengan keuangan koperasi. Materi diberikan mengenai pemahaman laporan keuangan dan tujuan adanya laporan keuangan agar peserta mengetahui pentingnya laporan keuangan. Setelah itu diberikan materi yang yang terkait kasus laporan keuangan. pada akhir pelaksanaannya, para peserta dapat memahami materi terlihat dengan antusiasnya peserta dalam berdiskusi dan pengerjaan kasus.

\section{SARAN}

Berdasarkan kegiatan yang sudah dilakukan,Koperasi Koperasi Sang Bumi Ruwa Juraidiharapkan melakukan pencatatan secara 
lengkap mengenai aktivitas operasinya, melakukan siklus akuntansi secara lengkap melakukan klasifikasipos-pos laporan keuangan yaitu dengan melakukan identifikasi, pengakuan, pengukuran, pencatatan, penyajian, dan pengungkapan laporan keuangansesuai standar yang berlaku. Diharapkan pula dapat membuat laporan keuangan secara benar, meliputi Laporan Laba Rugi, laporan perubahan Modal, laporan Neraca, Laporan Arus Kas, dan catatan atas laporan keuangan.Peningkatan sarana dan prasarana yang mendukung penyusunan laporan keuangan perlu dilakukan. Misalnya dengan penyediaan komputer dan aplikasi pendukungnya untuk mempermudah pencatatan keuangan yang akurat dan efisien serta melakukan peningkatan dan pengembangan pendidikan anggota melalui pelaksanaan pelatihan dan penyuluhan penyusunan laporan keuangan koperasi yang dilakukan secara rutin dan berkala. Dan ayng terakhir, adanya pengawasan dari anggota koperasi, pihak investor, masyarakat, dan pemerintah agar penyusunan laporan keuangan sesuai aturan yang berlaku umum dan transparan.

\section{UCAPAN TERIMA KASIH}

Penulis mengucapkan terimakasih kepada Fakultas Ekonomi dan LPPM Universitas Sang Bumi Ruwa Jurai yang telah memberikan dukungan dan apresiasi terhadap pengabdian ini. Terima kasih juga kepada seluruh peserta yang sudah meluangkan waktunya dalam mengikuti acara pelatihan ini.

\section{DAFTAR PUSTAKA}

[1] Rumayah, "Pelaksanaan Program Pemberdayaan Dan Kesejahteraan Keluarga (PKK) Dalam Pemberdayaan Masyarakat Di Desa Malinau Kota Kecamatan Malinau," eJournal Pemerintah. Integr., vol. 3, no. 2, pp. 323335, 2015, [Online]. Available: ejournal.pin.or.id/site/wpcontent/.../04/EJOURNAL (04-30-15-1112-15).pdf.

[2] A. Muslimat, "Rendahnya Partisipasi Wanita di Bidang Politik," J. Stud. Gend. dan Anak, vol. 3, no. 2, pp. 17-30, 2017.

[3] A. Toni, "Representasi Perempuan Indonesia Dalam Ajang Penghargaan Televisi (Studi Feminisme pada Penghargaan Indihome Women Award Di Metro TV)," J. ASPIKOM, vol. 2, no. 2, p. 103, 2014, doi: 10.24329/aspikom.v2i2.63.

[4] M. Rosana, "Kebijakan Pembangunan Berkelanjutan Yang Berwawasan Lingkungan di Indonesia," KELOLA J. Ilmu Sos., vol. 1, no. 1, pp. 148-163, 2018.

[5] S. M. U. Khabibah and P. E. Purnamasari, "Struktur Modal pada UMKM Tahu di Kelurahan Tinalan Gang IV Kota Kediri dan Menurut Perspektif Islam," J. Manaj., vol. 11, no. 1, pp. 95-113, 2020, doi: 
10.32832/jm-uika.v11i1.3031.

[6] P. Moengin, I. N. Firdaus, and S. Adisuwiryo, "Perancangan Model Simulasi Tata Letak Gudang Bahan Baku Menggunakan Metode Shared Storage Pada PT. Hyundai Indonesia Motor," $J$. Tek. Ind., vol. 8, no. 2, pp. 115-132, 2018.

[7] M. Suyanto and M. Abdulrahim, "Pengembangan Industri Sandal Asron Nafik Desa Wedoro, Kecamatan Waru, Kabupaten Sidoarjo,” J. Community Serv. Consort., vol. 1, no. 1, pp. 50-56, 2020.

[8] H. Halmawati, L. Fridayati, and A. Rafni, "PKM Usaha Dendeng Rinuak di KUB Dapur 21 Kenagarian Lubuk Basung Melalui Pelatihan Penyusunan Harga Pokok Produksi Dengan Metode Job Order Costing dan Inovasi Produk Makanan," $J$. Eksplor. Akunt., vol. 2, no. 4, pp. 35583565, 2020, doi: 10.24036/jea.v2i4.304.

[9] Habibah, L. A. Margie, A. P. Pratiwi, Afridayanti, and M. Ridwan, "Pelatihan Akuntansi dan Pengelolaan Keuangan pada UMKM Ratengan," Abdi Laksana J. Pengabdi. Kpd. Masy., vol. 2, no. 3, pp. 430-437, 2021.

[10] Mabruroh, A. N. Praswati, W. Mukharomah, T. Pratika, and L. Agustina, "Tata Kelola dan Lokasi Taman Edukasi Bijak Kelola Sampah," Abdi Psikonomi, vol. 1, no. 1, pp. 43-50, 2020.

[11] J. T. Wibowo, R. A. Kinseng, and T. Sumarti, "Dinamika Modal Sosial Nelayan
Dalam Arena Ekonomi: Studi Kasus Nelayan Rajungan Desa Betahwalang, Kecamatan Bonang, Kabupaten Demak," J. Sosiol. Reflektif, vol. 11, no. 1, pp. 139154, 2016, doi: 10.14421/jsr.v11i1.1276.

[12] B. A. Rukiyanto, "Peran Gereja Katolik Dalam Membangun Bangsa Indonesia Di Era Reformasi," Diskurs. - J. Filsafat Dan Teol. Stf Driyarkara, vol. 16, no. 2, pp. 105-137, 2017, doi: 10.26551/diskursus.v16i2.58.

[13] A. Hidayat and P. Safitri, "Pengembangan Komoditas Rumput Laut Nusa Tenggara Barat Dengan Model Hexagon Untuk Pembangunan Ekonomi Lokal," $J$. Kebijak. Sos. Ekon. Kelaut. dan Perikan., vol. 9, no. 1, pp. 45-56, 2019, doi: 10.15578/jksekp.v9i1.7359. 